\title{
Application of machine learning algorithms for predicting internal carotid artery stenosis and comparing their value to duplex Doppler ultrasonography criteria
}

\author{
Internal karotid arter darlığını tahmin etmede makine öğrenme algoritmalarının \\ kullanımı ve öngörüm başarısının dubleks Doppler ultrasonografi kriterleriyle \\ karşılaştırılması
}

Pınar Çeltikçi, Önder Eraslan, Mehmet Ali Atıcı, Işık Conkbayır, Onur Ergun, Hasanali Durmaz, Emrah Çeltikçi

Gönderilme tarihi:24.06.2021

Kabul tarihi:24.09.2021

\begin{abstract}
Purpose: There is a discrepancy between duplex Doppler ultrasonography (DUS) and digital subtraction angiography (DSA) for determining internal carotid artery (ICA) stenosis. We aim to train machine learning algorithms (MLAs) with DUS velocity values for predicting ICA stenosis and comparing their success to DUS criteria.

Materials and methods: DUS values (peak systolic velocity (PSV) and end-diastolic velocity of the common carotid artery (CCA) and ICA) and DSA studies of 159 ICA stenoses were reviewed retrospectively. Stenoses were classified as $<50 \%, 50-69 \%, \geq 70 \%$ by each modality. Linear regression models with descriptive and predictive analysis and MLAs; LightGBM, XgBoost, KNeighbors, Support Vector Machine (SVM), Decision Tree, Random Forest were trained with DUS values for predicting DSA stenosis.

Results: Predicted values of regression models have a linear relationship with DSA stenosis between 0-60\%. LightGBM and SVM achieved the highest classification accuracy $(69 \%)$, while all algorithms failed in the $50-$ $69 \%$ interval. DUS criteria outperformed all MLAs in predicting DSA stenosis of $\geq 70 \%$ (sensitivity:0.91). Both MLAs and DUS criteria were unsuccessful in the 50-69\% interval where DUS mostly overestimates and MLAs underestimate. MLAs using ICA PSV/CCA PSV ratio had higher accuracy for predicting DSA stenosis $<50 \%$. Conclusion: DUS criteria could be considered as the sole diagnostic tool for ICA stenosis over $70 \%$. Improved DUS criteria or wider training datasets for MLAs are warranted to detect $50-69 \%$ stenosis accurately.
\end{abstract}

Key words: Carotid artery, duplex Doppler ultrasonography, digital subtraction angiography, machine learning, stenosis.

Celtikci P, Eraslan O, Atici MA, Conkbayir I, Ergun O, Durmaz H, Celtikci E. Application of machine learning algorithms for predicting internal carotid artery stenosis and comparing their value to duplex Doppler ultrasonography criteria. Pam Med J 2022;15:213-222.

Öz

Amaç: İnternal karotid arter (IKKA) darlığını belirlemede, dupleks Doppler ultrasonografi (DUS) ile dijital subtraksiyon anjiyografi (DSA) arasında tutarsızlık bildirilmiştir. DUS hız değerleri ile eğitilmiş makine öğrenme algoritmalarının (MÖA), İKA darlığını tahmin etme performansını araştırmayı amaçlıyoruz.

Gereç ve yöntem: IKKA darlığı olan 159 karotid bifurkasyonunun, ortak karotid arter (OKA) ve IKA'dan elde olunmuş DUS hız değerleri (pik sistolik hız (PSH) ve diyastol sonu hızı) ve DSA tetkikleri retrospektif olarak incelendi. Darlık derecesi her modaliteye göre $<\% 50, \% 50-69, \geq \% 70$ olarak sınıflandırıldı. Tanımlayıcı ve kestirimci analizler içeren doğrusal regresyon modelleri ve çeşitli MÖA'lar (LightGBM, XgBoost, KNeighbors, Support Vector Machine (SVM), Decision Tree, Random Forest) DSA'da saptanan darlık derecesini tahmin etmek için DUS hız değerleri ile eğitildi.

Bulgular: Regresyon modellerinin tahmin ettiği darlık değerleri ve ası DSA darlık değerleri, \%0-60 arasında doğrusal bir ilişkiye sahipti. MÖA'lar arasında LightGBM ve SVM en yüksek sınıflandırma doğruluğunu (\%69)

Pınar Çeltikçi, M.D. Department of Radiology, Ankara Bilkent City Hospital, Ankara, Turkey, e-mail: drpinarceltikci@gmail.com (https://orcid. org/0000-0002-1655-6957) (Corresponding Author)

Önder Eraslan, M.D. Department of Radiology, Erbaa State Hospital, Tokat, Turkey, e-mail: ondereraslan@gmail.com (https://orcid.org/00000001-8904-1412)

Mehmet Ali Atıcı, M.S. Department of Computer Engineering, Gazi University Faculty of Engineering, Ankara, Turkey, e-mail: machinelearningdynamics@gmail.com (https://orcid.org/0000-0002-0673-5724)

Işık Conkbayır, M.D. Prof. Department of Radiology, University of Health Sciences, Diskapi Yildirim Beyazit Training and Research Hospital, Ankara, Turkey, e-mail: iconkbayir@yahoo.com (https://orcid.org/0000-0003-2768-4871)

Onur Ergun, Assoc. Prof. Department of Radiology, University of Health Sciences, Diskapi Yildirim Beyazit Training and Research Hospital, Ankara, Turkey, e-mail: onurergun@yahoo.com (https://orcid.org/0000-0002-0495-0500)

Hasanali Durmaz, M.D. Department of Radiology, University of Health Sciences, Diskapi Yildirim Beyazit Training and Research Hospital, Ankara, Turkey, e-mail: dr.hasan.ali.durmaz@hotmail.com (https://orcid.org/0000-0003-1140-6666)

Emrah Çeltikçi, M.D. Department of Neurosurgery, Gazi University Faculty of Medicine, Ankara, Turkey, e-mail: drceltikci@gmail.com (https:// orcid.org/0000-0001-5733-7542) 
elde ederken, tüm algoritmalar \%50-69 darlık aralığında başarısız oldu. DUS kriterleri, $\geq \% 70$ 'lik DSA darığını tahmin etmede tüm MÖA'lardan daha iyi performans gösterdi (duyarlıık:0,91). Hem MÖA'lar hem de DUS kriterleri \%50-69 darlık aralığında başarısız olup, DUS darlığı olduğundan fazla, MÖA'lar darlığı olduğundan az olarak tahmin etti. İKA PSH/OKA PSH oranını kullanan MÖA'lar, <\%50 DSA darlığını öngörmede daha yüksek doğruluğa sahipti.

Sonuç: DUS kriterleri, \%70'in üzerinde İKA darlığı için tek tanı aracı olarak kabul edilebilir. Geliştirilmiş DUS kriterleri veya MÖA'lar için daha geniş eğitim veri setleri sağlanması, \%50-69 darlık aralığının daha yüksek doğrulukla tespit edilmesini sağlayabilir.

Anahtar kelimeler: Darlık, dijital subtraksiyon anjiyografi, dupleks Doppler ultrasonografi, karotid arter, makine öğrenmesi.

Çeltikçi P, Eraslan Ö, Atıcı MA, Conkbayır I, Ergun O, Durmaz H, Çeltikçi E. İnternal karotid arter darlığını tahmin etmede makine öğrenme algoritmalarının kullanımı ve öngörüm başarısının dubleks Doppler ultrasonografi kriterleriyle karşılaştııılması. Pam Tıp Derg 2022;15:213-222.

\section{Introduction}

Detection and accurate quantification of extracranial internal carotid artery (ICA) stenosis is of great importance in order to prevent morbidity and mortality by secondary cerebrovascular ischemic events $[1,2]$. Main goal is to detect carotid artery atherosclerotic disease and determine the stenosis degree, so that patients are selected either for conservative treatment or surgery. Patients with stenosis rates exceeding $70 \%$ have shown to benefit from endarterectomy [3]. Digital subtraction angiography (DSA) is the gold standard method for estimating stenosis percentage. However, DSA is an invasive and expensive procedure which requires access to an angiography suite, trained personnel, as well as exposure to ionizing radiation and administration of iodinated contrast agent which might compromise renal function. Computed tomography angiography and magnetic resonance imaging angiography are less invasive options, which also entail contrast media administration and/or radiation exposure nevertheless.

Duplex Doppler ultrasonography (DUS) is a non-invasive, rapid, safe, and low-cost technique, therefore considered as the first line of choice for evaluating patients with suspected carotid atherosclerotic disease. The value of DUS for the detection and classification of the atherosclerotic disease of the carotid arteries is widely investigated. There are various DUS parameters and criteria proposed in the literature [4-6]. Overall high rates of performance parameters were reported for the Society of Radiologists in Ultrasound Consensus Conference criteria. However, the precise determination of ICA stenosis rate with DUS and the agreement between DUS and
DSA are still a matter of debate in the current literature [7-14].

Machine learning algorithms are increasingly utilized for detecting possible relationships and patterns in the medical field. To the best of our knowledge, machine learning classifier algorithms have never been utilized to predict DSA stenosis rates of extracranial ICA stenosis following training with velocity data in comparison to DUS criteria. Here, we aim to investigate the correlation between DUS and DSA for the classification of ICA stenosis, and to train multiple machine learning algorithms with DUS velocity values in order to reveal their success in predicting DSA stenosis and compare them to DUS criteria.

\section{Materials and methods}

Prior to the study, the Local Ethics Committee approval and informed written consent from all patients were obtained.

\section{Patient selection}

All patients that were referred to the Vascular Ultrasonography Unit of the fourth listed institution, for carotid artery DUS examination, between March 2013-November 2018 and diagnosed with ICA stenosis were considered for this retrospective study. Following the elimination of vessels without a DSA study followed by the DUS evaluation, 198 patients underwent further evaluation of DUS examination reports and DSA studies. The average time interval between DUS and DSA examinations were 26 days. Exclusion criteria were; previous history of carotid artery surgery, occlusion and near occlusion, suboptimal image quality. Following exclusion, 159 ICAs of 123 patients constituted the study cohort. 


\section{DUS evaluation}

DUS studies were performed by two radiologists with $10+$ and $20+$ year experience, using an Aplio ${ }^{\mathrm{TM}} 500$ ultrasound machine (TUS-A500) (Toshiba Medical Systems, Otawara, Japan) with 6-12 MHz linear array transducers. All DUS studies were performed prior to angiography. Common carotid artery (CCA), bifurcation, ICA and external carotid arteries of both sides were evaluated. Grayscale imaging in longitudinal and axial planes, color mode and spectral imaging were utilized in all cases. Gray-scale examination included evaluation of arterial walls and lumens and measurement of atherosclerotic plaques. Angleadjusted spectral DUS images were obtained from CCA approximately 2 centimeters proximal to the bifurcation and at the ICA stenosis. Highest peak systolic velocity (PSV) and end-diastolic velocity (EDV) measured of both CCA and ICA were recorded. Stenosis percentage was calculated according to Society of Radiologists in Ultrasound Consensus Conference criteria and classified as $<50 \%, 50-69 \%$ and $\geq 70 \%$ [6].

\section{DSA evaluation}

DSA studies were performed by a $15+$ year experienced interventional radiologist using an Artis zee floor interventional angiography system (Siemens, Germany). Omnipaque 350® (lohexol, GE Healthcare, Milwaukee, WI, USA) was utilized as contrast agent in all examinations. Unilateral or bilateral carotid arterial system was examined through femoral artery puncture. At least two orthogonal views of ICA and CCA at bifurcation were acquired following selective catheterization. DSA studies were evaluated by the same interventional radiologist blinded to DUS results and clinical information. ICA stenosis percentage was calculated according to The North American Symptomatic Carotid Endarterectomy Trial (NASCET) criteria and then categorized as $<50 \%, 50-69 \%$ and $\geq 70 \%$ [1].

Table 1. Confusion Matrix

\section{Data analysis}

Both linear regression model with descriptive and predictive analysis, and machine learning algorithms were employed for data analysis. Python Sci-kit Learn (https://scikit-learn.org/ stable/), Numpy (https://numpy.org/), Pandas (https://pandas.pydata.org/), Matplotlib (https://matplotlib.org/) and Seaborn (https:// seaborn.pydata.org/) libraries were utilized. For descriptive analysis, Pearson correlations matrix is calculated. Pearson correlation coefficient measures the linear relationship between random variables and takes values between -1 and +1 such that 0 means no relation whereas -1 and +1 means perfect association. The values between 0.5 and 0.8 indicates a moderate relationship between the variables whereas the values between -0.2 and +0.2 point out weak association [15]. In predictive analysis, simple linear regression was applied. Dependent variables were predicted by the predictor variable. Linear regression model was trained for predicting the DSA stenosis value (\%) from ICA PSV and ICA EDV separately. Training was on basis of $k$-fold cross validation $(k=5)$.

Second, machine learning algorithms were trained for classifying the DSA stenosis intervals from ICA PSV, ICA EDV, CCA PSV and CCA EDV values. For this, DSA stenosis values in the dataset were divided into 3 classes as; class 1: $<50 \%$, class 2: $50-69 \%$, class 3 : $\geq 70 \%$. We also trained classifiers that takes only ICA PSV/CCA PSV ratio as the input. In experiments, 6 different machine learning algorithms (LightGBM, XgBoost, K Neighbors, Support Vector Machines (SVM), Decision Tree and Random Forest) were implemented for classification. Training was on basis of $k$-fold cross validation $(k=19)$. Performance of the classifiers have been evaluated by accuracy, precision, recall and F1-measure metrics calculated according to confusion matrix are elaborated in Table 1.

\begin{tabular}{lll}
\hline & Predicted Negative & Predicted Positive \\
\hline Actual Negative & True Negative (TN) & False Positive (FP) \\
Actual Positive & False Negative (FN) & True Positive (TP) \\
\hline
\end{tabular}

Accuracy, precision, sensitivity and F1-measure can be formally calculated as; Precision=TP/(TP+FP), Recall=Sensitivity $=T P /(T P+F N)$, Accuracy $=(T P+T N) /(T P+F N+T N+F P)$ and $F 1-$ measure $=2 /((1 /$ precision $)+(1 /$ recall $))$ 


\section{Results}

A total of 159 carotid artery bifurcations constituted the study cohort. Stenosis percentage ranged from $0-91 \%$ by DSA. PSV measurement ranged from $62-720 \mathrm{~cm} / \mathrm{s}$ in ICA and $18-110 \mathrm{~cm} / \mathrm{s}$ in CCA. EDV measurement ranged from $10-390 \mathrm{~cm} / \mathrm{s}$ in ICA and $5-30 \mathrm{~cm} / \mathrm{s}$ in CCA. The ratio of ICA/CCA PSV ranged from 1.2-20.

Pearson correlations matrix with pairwise Pearson correlation coefficient calculations of ICA PSV, ICA EDV, CCA PSV, CCA EDV and DSA stenosis percentage were presented in Figure 1. There is a moderate correlation between DSA stenosis percentage and both
ICA PSV and ICA EDV according to Pearson correlation coefficient calculations; which are 0.66 and 0.58 respectively. On the other hand, there is weak association between DSA stenosis percentage and CCA PSV, CCA EDV values.

The scattered plots of these values against DSA stenosis percentages supports the findings from the correlation matrix. There is a linear relationship between DSA stenosis percentage and ICA PSV and ICA EDV to some extent (Figure 2A and Figure 2B). However, randomly scattered values do not provide an evidence for linear relationship between DSA stenosis percentage and CCA PSV or CCA EDV (Figure $2 \mathrm{C}$ and Figure 2D).

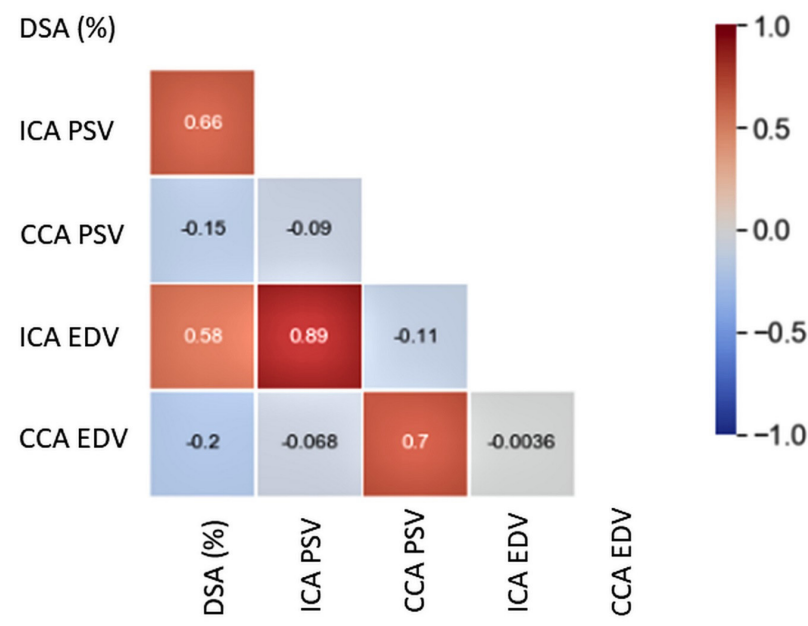

Figure 1. Pearson correlations matrix with pairwise Pearson correlation coefficient calculations of internal carotid artery peak systolic velocity (ICA PSV), internal carotid artery end-diastolic velocity (ICA EDV), common carotid artery peak systolic velocity (CCA PSV), common carotid artery enddiastolic velocity (CCA EDV) and digital subtraction angiography (DSA) stenosis percentage
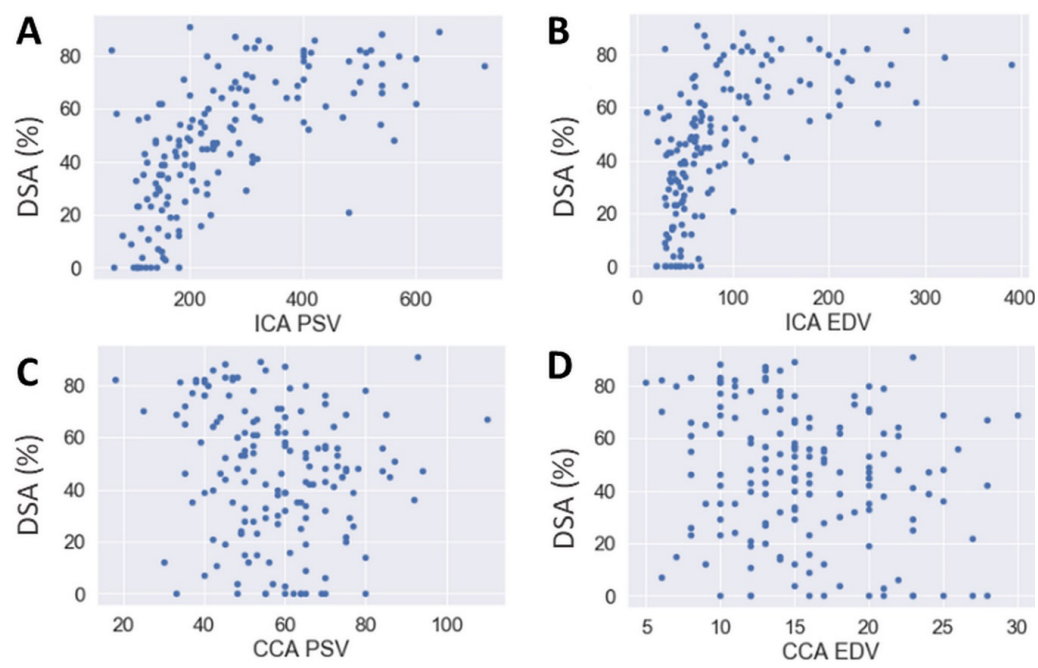

Figure 2. The scattered plots of internal carotid artery peak systolic velocity (ICA PSV), internal carotid artery end-diastolic velocity (ICA EDV), common carotid artery peak systolic velocity (CCA PSV), common carotid artery end-diastolic velocity (CCA EDV) values against digital subtraction angiography (DSA) stenosis percentages 
Two linear regression models were trained for predicting DSA stenosis percentage from ICA PSV and ICA EDV. These two values were utilized due to the fact that there was a moderate correlation according to Pearson correlation coefficient calculations. The achieved $\mathrm{R}^{2}$ scores (coefficient of determination), which equals to square of Pearson correlation coefficient for each trained model of ICA PSV and ICA EDV was 0.43 and 0.33 , respectively. In accordance with descriptive analysis results, these results indicate that ICA PSV has more impact for predicting DSA stenosis percentage than ICA EDV. The scattered plots of predicted DSA stenosis percentage against actual percentage is demonstrated in Figure 3. The predicted values of trained regression models have a linear relationship with actual DSA stenosis percentages to some extent but there is some corruption above $60 \%$ and around $0 \%$ values.

Confusion matrices for each machine learning classifier trained with both ICA PSV and CCA PSV are given in Figure 4.

\section{ICA PSV}

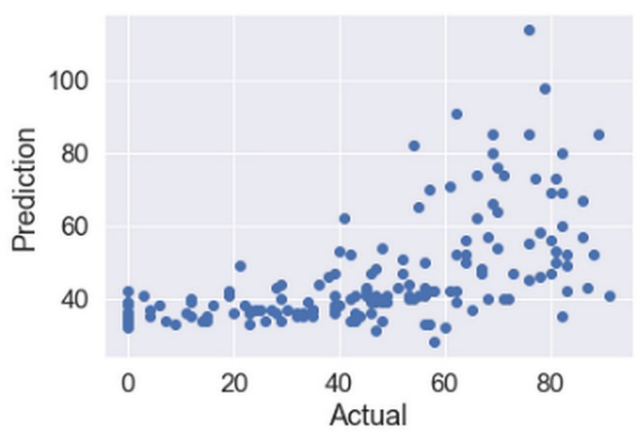

Performance metrics of the classifiers are given in Table 2. Results in Table 2 indicate that LightGBM and SVM algorithms achieved the highest classification accuracy which is $69 \%$. LightGBM achieved the highest sensitivity for DSA stenosis $50-69 \%$ interval when compared to other algorithms. It is clear that all algorithms fail for classification of $50-69 \%$ interval. This result is demonstrated on the $2 \mathrm{D}$ scattered plots of data samples in reduced dimension by Linear Discriminant Analysis (LDA). Samples for 50$69 \%$ interval are scattered across the both of clusters of other classes (Figure 5).

Additionally, confusion matrices of classifier algorithms using ICA PSV/CCA PSV ratio as the input improves the classification accuracy up to 0.74 and sensitivity for DSA stenosis $<50 \%$ cases up to 0.98 (Figure 6). However, general accuracy of DUS is too low when compared the machine learning classifiers (Table 3 ) which is 0.33 ; even worse than random guess. For subjects with DSA stenosis $<50 \%$, sensitivity (recall) is too low again and DUS overestimates

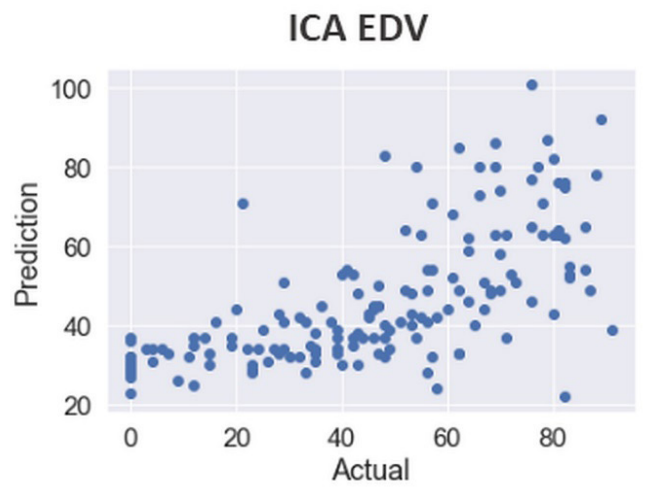

Figure 3. The scattered plots of predicted digital subtraction angiography (DSA) stenosis percentage against actual percentage; internal carotid artery peak systolic velocity (ICA PSV), internal carotid artery end-diastolic velocity (ICA EDV)

Table 2. Performance metrics of classifier machine learning algorithms trained with internal carotid artery peak systolic velocity and common carotid artery peak systolic velocity

\begin{tabular}{lllllllllll}
\hline & $<50 \%$ & \multicolumn{3}{c}{$50-69 \%$} & \multicolumn{3}{c}{$>70 \%$} & & \multicolumn{2}{c}{ General } \\
Classifier & $P$ & $\mathrm{R}$ & $\mathrm{F} 1$ & $\mathrm{P}$ & $\mathrm{R}$ & $\mathrm{F} 1$ & $\mathrm{P}$ & $\mathrm{R}$ & $\mathrm{F} 1$ & $\begin{array}{l}\text { Accuracy } \\
(\%)\end{array}$ \\
& $(\%)$ & $(\%)$ & $(\%)$ & $(\%)$ & $(\%)$ & $(\%)$ & $(\%)$ & $(\%)$ & $(\%)$ & $(\%)$ \\
\hline KNeighbors & 76 & 87 & 81 & 23 & 15 & 18 & 44 & 44 & 44 & 60 \\
Random Forest & 76 & 91 & $\mathbf{8 3}$ & 36 & 21 & 26 & 63 & $\mathbf{6 5}$ & 64 & 68 \\
SVM & 72 & $\mathbf{9 4}$ & 82 & 43 & 15 & 23 & 67 & $\mathbf{6 5}$ & 66 & 69 \\
Decision Tree & 76 & 83 & 79 & 23 & 15 & 18 & 49 & 56 & 52 & 60 \\
XGBoost & 76 & 81 & 79 & 31 & 31 & 31 & 61 & 50 & 55 & 62 \\
LightGBM & $\mathbf{7 7}$ & 87 & 82 & $\mathbf{4 7}$ & $\mathbf{3 6}$ & $\mathbf{4 1}$ & $\mathbf{6 9}$ & $\mathbf{6 5}$ & $\mathbf{6 7}$ & $\mathbf{7 0}$ \\
\hline
\end{tabular}

$P$ : precision, R: recall, F1: F1 measure, SVM: support vector machine 

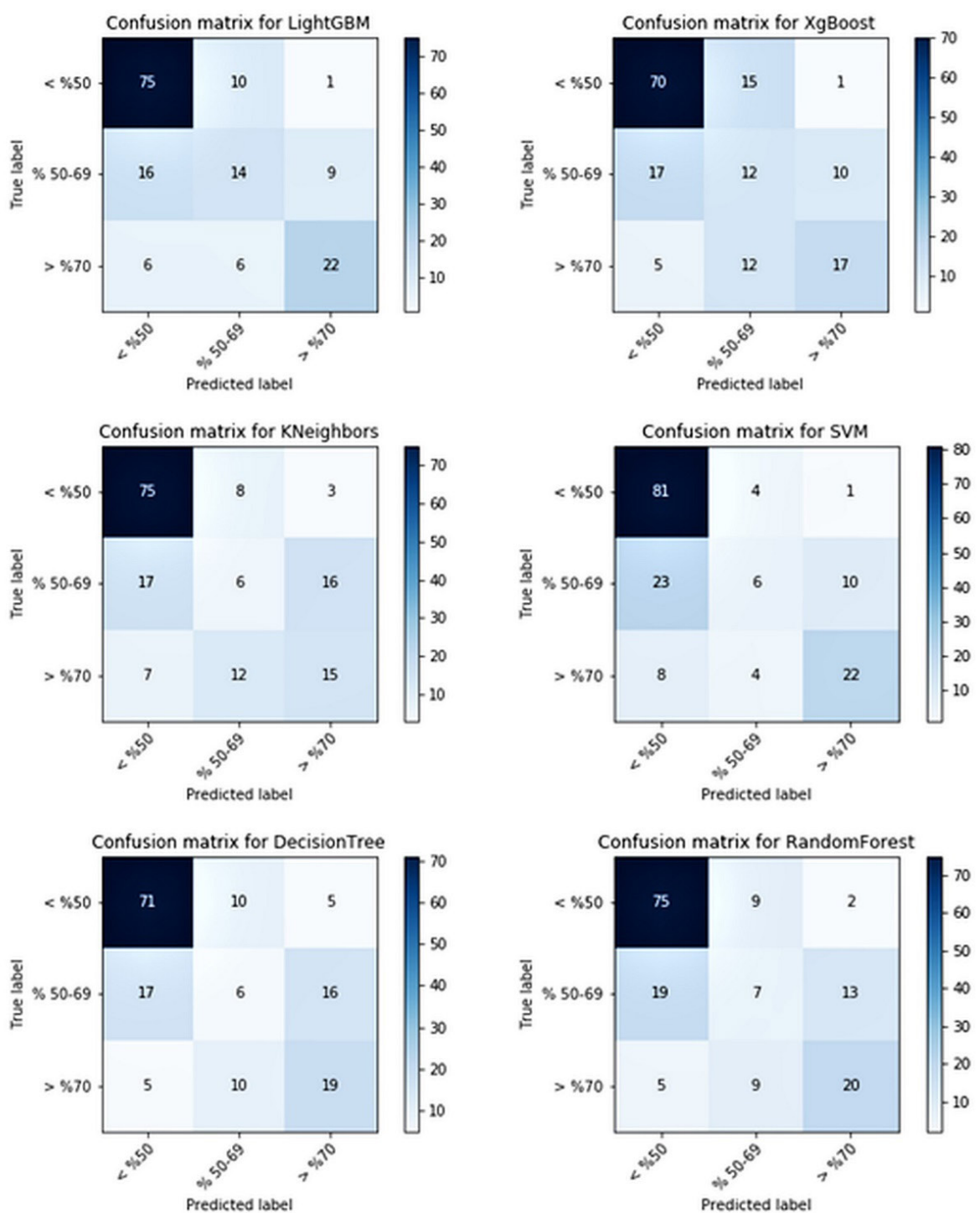

Figure 4. Confusion matrices for each machine learning classifier which are trained with internal carotid artery peak systolic velocity (ICA PSV) and common carotid artery peak systolic velocity (CCA PSV); LightGBM, XgBoost, KNeighbors, Support Vector Machine (SVM), Decision Tree, and Random Forest
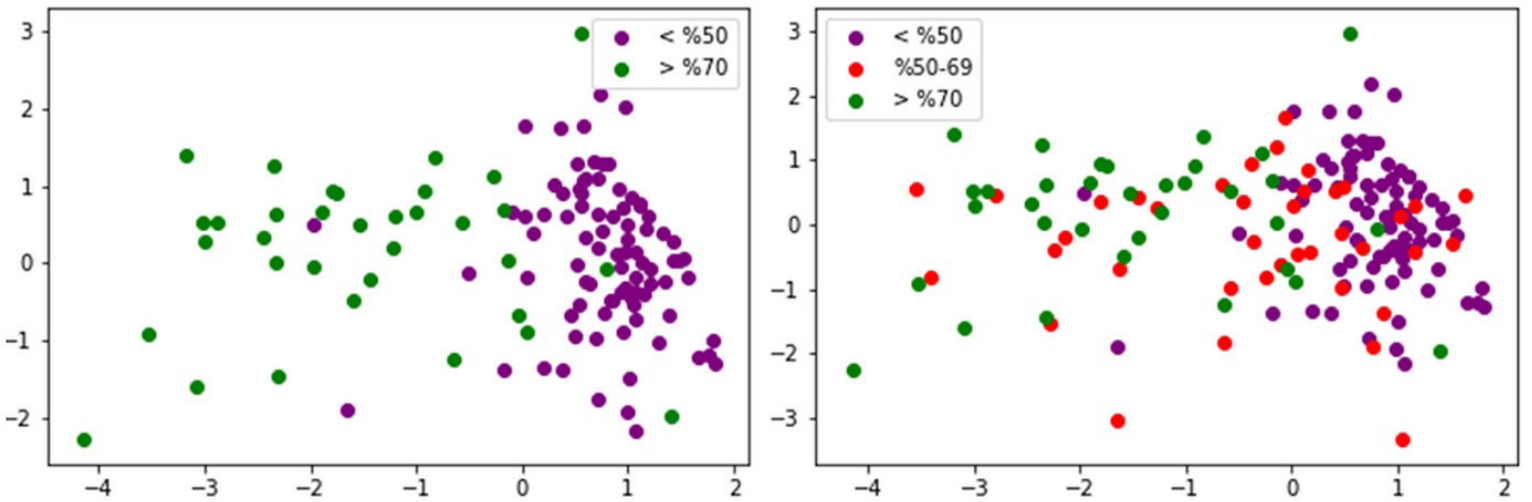

Figure 5. Linear Discriminant Analysis (LDA) scattered plots of data samples reveal that samples of $<50 \%$ stenosis (purple dots) and samples of $>70 \%$ stenosis (green dots) are almost distinguished from each other (left) forming mostly separate clusters. However, samples of $50-69 \%$ stenosis (red dots) are scattered across both clusters of other classes (right) which demonstrates the failure of machine learning classifiers in this stenosis range 
Table 3. Performance metrics of classifier machine learning algorithms trained with internal carotid artery peak systolic velocity/common carotid artery peak systolic velocity ratio and duplex Doppler ultrasonography criteria

\begin{tabular}{lllllllllll}
\hline \multirow{2}{*}{ Classifier } & $<50 \%$ & \multicolumn{3}{c}{$50-69 \%$} & \multicolumn{3}{c}{$>70 \%$} & \multicolumn{3}{c}{ General } \\
& $P$ & $\mathrm{R}$ & $\mathrm{F} 1$ & $\mathrm{P}$ & $\mathrm{R}$ & $\mathrm{F} 1$ & $\mathrm{P}$ & $\mathrm{R}$ & $\mathrm{F} 1$ & Accuracy \\
& $(\%)$ & $(\%)$ & $(\%)$ & $(\%)$ & $(\%)$ & $(\%)$ & $(\%)$ & $(\%)$ & $(\%)$ & $(\%)$ \\
\hline KNeighbors & $\mathbf{7 5}$ & 88 & 81 & 42 & 26 & 32 & 67 & 63 & 65 & 68 \\
Random Forest & $\mathbf{7 8}$ & 87 & 82 & 47 & 39 & 43 & 61 & 54 & 58 & 69 \\
SVM & 72 & $\mathbf{9 8}$ & 83 & 40 & 11 & 17 & 62 & 57 & 60 & 68 \\
Decision Tree & $\mathbf{7 8}$ & 85 & 81 & 43 & 39 & 41 & 60 & 51 & 55 & 67 \\
XGBoost & $\mathbf{7 8}$ & 87 & 82 & 47 & $\mathbf{3 9}$ & 43 & $\mathbf{6 8}$ & 60 & 64 & 70 \\
LightGBM & $\mathbf{7 7}$ & $\mathbf{9 7}$ & $\mathbf{8 6}$ & $\mathbf{8 0}$ & 32 & $\mathbf{4 5}$ & 64 & 66 & $\mathbf{6 5}$ & $\mathbf{7 4}$ \\
DUS & $\mathbf{9 2}$ & $\mathbf{1 3}$ & $\mathbf{2 2}$ & $\mathbf{1 3}$ & $\mathbf{2 6}$ & $\mathbf{1 7}$ & $\mathbf{4 6}$ & $\mathbf{9 1}$ & $\mathbf{6 2}$ & $\mathbf{3 3}$ \\
\hline
\end{tabular}

$P$ : precision, R: recall, F1: F1 measure, DUS: Duplex Doppler Ultrasonography

SVM: support vector machine

almost $87 \%$ of the subjects. On the other hand, DUS is more successful than machine learning algorithms with respect to subjects with DSA stenosis $\geq 70 \%$, whereas achieves 0.91 sensitivity. Both machine learning algorithms and DUS are unsuccessful for predicting DSA stenosis of $50-69 \%$. One difference is that DUS mostly overestimates the incorrect predictions whereas machine learning algorithms underestimate. This may be related to both data set and the algorithm. For instance, confusion matrix of $\mathrm{K}$ Neighbors algorithm in Figure 6 indicates that numbers of overestimated and underestimated predictions are the same. When trained with a larger data set, machine learning algorithms may achieve higher sensitivity for DSA stenosis in the $50-69 \%$ interval.

\section{Discussion}

The results of this study indicate that DUS criteria and DSA show varying levels of discordance when calculating ICA stenosis, depending on the stenosis range, when a linear regression model and machine learning algorithms were applied. We believe the main reason behind this problem is the fact that, in each modality, a different indicator of stenosis is utilized. DUS criteria identifies stenosis via measurements regarding flow velocity, whereas catheter angiography measures the change in vessel calibration.

In our study, linear regression models showed ICA PSV value to be more predictive of the DSA stenosis rate with some corruption over $60 \%$. Our results are compatible with other studies from the literature which utilized regression models [16, 17]. However, with regression models, determining the success of DUS in predicting DSA stenosis, in each interval of $<50 \%, 50-69 \%$ and $\geq 70 \%$ as it classifies them, is not possible. After revealing the discordance between DUS criteria and DSA we trained machine learning algorithms with DUS data (both velocity values separately and ICA PSV/CCA PSV ratio), in order to see if they would perform any differently. Apart from a meta-analysis [18] which used a neural net algorithm to derive an equation relating ICA PSV/CCA PSV ratio to NASCET percent stenosis, our study is the only one in literature to apply multiple machine learning classifier algorithms on DUS velocity data for predicting DSA stenosis.

Machine learning algorithms are gaining wider recognition and application in the field of radiology. Currently, these methods are more commonly applied in image analysis and pattern recognition. Utilizing machine learning algorithms on numerical data such as flow velocity values is relatively uncommon. In our study, machine learning algorithms were more successful in predicting DSA stenosis rates below $50 \%$ than DUS criteria. This result is most likely due to the fact that, DUS criteria identifies stenosis by increased velocity which is not apparent in stenosis rates below $50 \%$. Both DUS criteria and machine leaning algorithms fail in the $50-69 \%$ range. In this range, success of DUS criteria is of debate and was shown to have discordance with statistical methods in various studies $[11,19,20]$. On the other hand, 

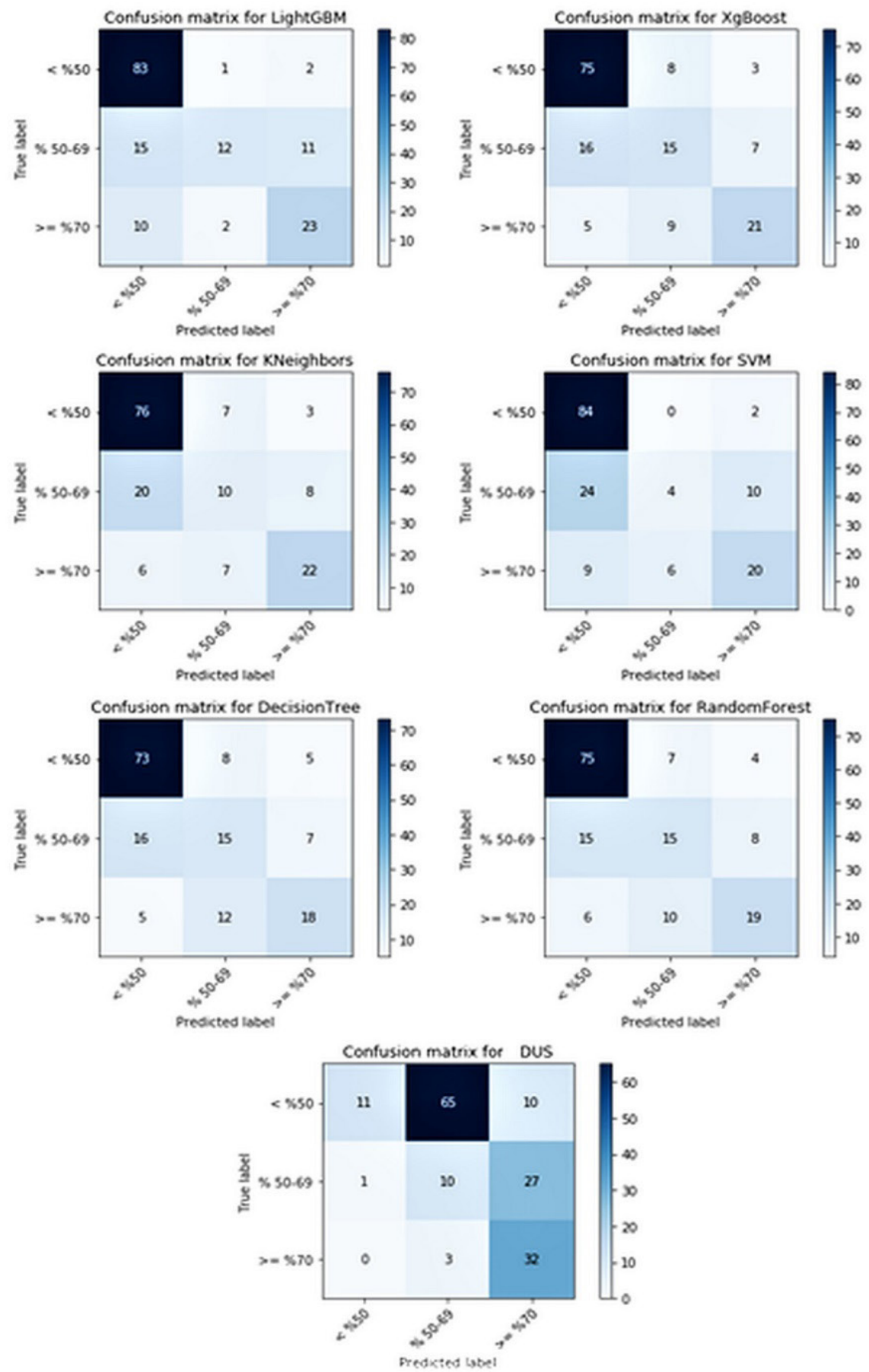

Figure 6. Confusion matrices of classifier algorithms; LightGBM, XgBoost, KNeighbors, Support Vector Machine (SVM), Decision Tree, and Random Forest, using internal carotid artery peak systolic velocity (ICA PSV)/common carotid artery peak systolic velocity (CCA PSV) ratio as the input

despite machine leaning algorithms failed to successfully predict stenosis in our study, this could be simply due to lack of sufficient data. Future studies with wider datasets to train machine learning algorithms may produce more satisfactory results, that might even replace DUS criteria in this stenosis range. This could lead to integration of machine leaning algorithms in ultrasound systems, which would provide unbiased clinical decisions.
DUS criteria predicted $\geq 70 \%$ stenosis more successfully than all machine learning algorithms. Current guidelines recommend surgical or minimally invasive interventions such as carotid artery stenting, depending on the symptom status of patients with stenosis levels higher than $60 \%-70 \%[21,22]$. Therefore, we conclude that, as current DUS criteria are dependable for the detection of stenosis rates higher than $\geq \% 70$, with optimized and standardized equipment and 
technique, this modality could be recommended as single preoperative diagnostic tool prior to intervention. Such diagnostic algorithm would prevent patients receiving unnecessary ionizing radiation and contrast media, as well as risks related to angiography procedure, shorten the diagnosis interval and hospitalization duration.

This study has several limitations. First, data utilized is retrospective. Second, study population is limited which might cause lower performance of classifier algorithms due to inadequate training. Our future perspective includes utilizing a multi-central big data analysis which would allow more accurate predictions.

In conclusion, DUS criteria can accurately detect ICA stenosis over $70 \%$, when compared to machine learning algorithms, which might lead to utilization of this modality as sole diagnostic tool provided that equipment and technique is optimal. Concordance of DUS criteria with DSA is low for detecting stenosis rates under $70 \%$, however, machine learning algorithms have substantially better performance in predicting DSA stenosis under $50 \%$. Improved DUS criteria or wider training datasets for training machine learning algorithms in order to accurately detect $50-69 \%$ stenosis is warranted. Further studies with wider datasets would establish the value of the combined use of DUS criteria and machine learning algorithms in determining extracranial ICA stenosis, using velocity measurements, that might lead to alterations in diagnostic algorithm.

Conflict of interest: No conflict of interest was declared by the authors.

\section{References}

1. North American Symptomatic Carotid Endarterectomy Trial Collaborators; Barnett HJM, Taylor DW, Haynes $\mathrm{RB}$, et al. Beneficial effect of carotid endarterectomy in symptomatic patients with high-grade carotid stenosis. N Engl J Med 1991;325:445-453. https://doi. org/10.1056/NEJM199108153250701

2. European Carotid Trialists' Collaborative Group. Randomised trial of endarterectomy for recently symptomatic carotid stenosis: final results of the MRC European Carotid Surgery Trial (ECST). Lancet 1998;351:1379-1387.

3. Endarterectomy for asymptomatic carotid artery stenosis. Executive committee for the asymptomatic carotid atherosclerosis study. JAMA 1995;273:14211428.
4. Arning C, Widder B, von Reutern GM, Stiegler $\mathrm{H}$, Görtler M. Revision of DEGUM ultrasound criteria for grading internal carotid artery stenoses and transfer to NASCET measurement. Ultraschall Med 2010;31:251257. https://doi.org/10.1055/s-0029-1245336

5. Hathout GM, Fink JR, El Saden SM, Grant EG. Sonographic NASCET index: a new doppler parameter for assessment of internal carotid artery stenosis. AJNR Am J Neuroradiol 2005;26:68-75.

6. Grant EG, Benson CB, Moneta GL, et al. Carotid artery stenosis: gray-scale and Doppler US diagnosis-Society of Radiologists in Ultrasound Consensus Conference. Radiology 2003;229:340-346. https://doi. org/10.1148/radiol.2292030516

7. Eliasziw M, Rankin RN, Fox AJ, Haynes RB, Barnett HJ. Accuracy and prognostic consequences of ultrasonography in identifying severe carotid artery stenosis. North American Symptomatic Carotid Endarterectomy Trial (NASCET) Group. Stroke 1995;26:1747-1752. https://doi.org/10.1161/01. str.26.10.1747

8. Ballard JL, Fleig K, De Lange M, Killeen JD. The diagnostic accuracy of duplex ultrasonography for evaluating carotid bifurcation. Am J Surg 1994;168:123126. https://doi.org/10.1016/s0002-9610(94)80050-2

9. Howard G, Baker WH, Chambless LE, Howard VJ, Jones AM, Toole JF. An approach for the use of Doppler ultrasound as a screening tool for hemodynamically significant stenosis (despite heterogeneity of Doppler performance). A multicenter experience. Asymptomatic Carotid Atherosclerosis Study Investigators. Stroke 1996;27:1951-1957. https://doi.org/10.1161/01. str.27.11.1951

10. Boyko M, Kalashyan $\mathrm{H}$, Becher $\mathrm{H}$, et al. Comparison of carotid Doppler ultrasound to other angiographic modalities in the measurement of carotid artery stenosis. J Neuroimaging 2018;28:683-687. https://doi. org/10.1111/jon.12532

11. Barlinn $\mathrm{K}$, Rickmann $\mathrm{H}$, Kitzler $\mathrm{H}$, et al. Validation of multiparametric ultrasonography criteria with digital subtraction angiography in carotid artery disease: a prospective multicenter study. Ultraschall Med 2018;39:535-543. https://doi. org/10.1055/s-0043-119355

12. Dean N, Lari H, Saqqur M, et al. Reliability of carotid doppler performed in a dedicated stroke prevention clinic. Can J Neurol Sci 2005;32:327-331. https://doi. org/10.1017/s0317167100004212

13. Wardlaw JM, Chappell FM, Best JJK, Wartolowska K, Beryy E. Non-invasive imaging compared with intra-arterial angiography in the diagnosis of symptomatic carotid stenosis: a meta-analysis. Lancet 2006;367:1503-1512. https://doi.org/10.1016/S01406736(06)68650-9

14. Gough MJ. Preprocedural imaging strategies in symptomatic carotid artery stenosis. J Vasc Surg 2011;54:1215-1218. https://doi.org/10.1016/j. jvs.2011.05.101 
15. Zou KH, Tuncali K, Silverman SG. Correlation and simple linear regression. Radiology 2003;227:617-622. https://doi.org/10.1148/radiol.2273011499

16. Carnicelli AP, Stone JJ, Doyle A, Chowdhry A, Gillespie DL, Chandra A. Predictive multivariate regression to increase the specificity of carotid duplex ultrasound for high-grade stenosis in asymptomatic patients. Ann Vasc Surg 2014;28:1548-1555. https://doi. org/10.1016/j.avsg.2014.02.010

17. Hathout G, Nayak N, Abdulla A, Huang J. The revised sonographic NASCET Index: a new hemodynamic parameter for the assessment of internal carotid artery stenosis. Ultraschall Med 2015;36:362-368. https://doi. org/10.1055/s-0034-1385070

18. Polak A, Polak JF. Internal to common carotid artery peak systolic velocity ratios for predicting north american symptomatic carotid endarterectomy trial stenosis: derivation/validation study using a machine learning technique. J Vasc Ultrasound 2019;43:182185. https://doi.org/10.1177/1544316719874576

19. AbuRahma AF, Srivastava $M$, Stone $P A$, et al. Critical appraisal of the Carotid Duplex Consensus criteria in the diagnosis of carotid artery stenosis. J Vasc Surg 2011;53:53-59. https://doi.org/10.1016/j. jvs.2010.07.045

20. BeachKW, LeottaDF,ZierlerRE. Carotid Dopplervelocity measurements and anatomic stenosis: correlation is futile. Vasc Endovascular Surg 2012;46:466-474. https://doi.org/10.1177/1538574412452159

21. Goldstein LB, Bushnell CD, Adams RJ, et al. Guidelines for the primary prevention of stroke: a guideline for healthcare professionals from the American Heart Association/American Stroke Association. Stroke 2011;42:517-584. https://doi.org/10.1161/ STR.0b013e3181fcb238

22. Brott TG, Halperin JL, Abbara S, et al. 2011 ASA/ ACCF/AHA/AANN/AANS/ACR/ASNR/CNS/ SAIP/SCAI/SIR/SNIS/SVM/SVS guideline on the management of patients with extracranial carotid and vertebral artery disease: executive summary. A report of the American College of Cardiology Foundation/American Heart Association Task Force on Practice Guidelines, and the American Stroke Association, American Association of Neuroscience Nurses, American Association of Neurological Surgeons, American College of Radiology, American Society of Neuroradiology, Congress of Neurological Surgeons, Society of Atherosclerosis Imaging and Prevention, Society for Cardiovascular Angiography and Interventions, Society of Interventional Radiology, Society of Neurolnterventional Surgery, Society for Vascular Medicine, and Society for Vascular Surgery. Circulation 2011;124:489-532. https://doi.org/10.1161/ CIR.0b013e31820d8d78
Ethics committee approval: Prior to the study, the Local Ethics Committee approval was obtained from University of Health Sciences Ankara Diskapi Yildirim Beyazit Training and Research Hospital (date: 12 November 2018, issue number: 56/09). All procedures performed in the studies involving human participants were in accordance with the ethical standards of the institutional and/or national research committee and with the 1964 Helsinki Declaration and its later amendments or comparable ethical standards.

\section{Authors' contributions}

P.C., I.C. and O.E. conceived the idea. O.E. collected the data. M.A.A. performed the calculations, data analysis and created figures. P.C., M.A.A. and E.C. interpreted and discussed the results. E.C. and H.A.D. provided critical feedback. P.C. wrote the manuscript with input from all authors. All authors discussed the results, reviewed and commented on the manuscript. 